\title{
Successful Revascularization of Coronary Artery Occluded by Massive Intracoronary Thrombi with Alteplase and Percutaneous Coronary Intervention
}

\author{
Jeong Su Kim 1,2, June Hong Kim 1,2, Hyung Ha Jang ${ }^{1,2}$, Yong Whan Lee ${ }^{1,2}$, Sung Gook Song ${ }^{1,2}$, \\ Ju Hyun Park ${ }^{1,2}$, and Kook Jin Chun ${ }^{1,2}$ \\ ${ }^{1}$ Department of Internal Medicine, Pusan National University School of Medicine, Yangsan, Korea \\ ${ }^{2}$ Division of Cardiology, Cardiovascular Center, Pusan National University Yangsan Hospital, Yangsan, Korea
}

\begin{abstract}
A 67-year-old man was admitted to our institution with sudden and pessistant chest pain for 3 days. Coronary angiography showed massive thrombotic occlusion of the right coronary artery. The patient received intracoronary thrombolysis with alteplase (recombinant tissue-type plasminogen activator, rt-PA). On repeated angiography, there was marked resolution of intracoronary thrombus. After percutaneous coronary intervention with stent implantation, the final result was complete revascularization of the right coronary artery (TIMI grade 3 distal flow). This case demonstrates that intracoronary rt-PA can result in local thrombus reduction in patients undergoing PCI, especially with a large thrombus burden.
\end{abstract}

J Atheroscler Thromb, 2010; 17:768-770.

Key words; Myocardial infarction, Thrombolytic therapy, Percutaneous Transluminal Coronary Angioplasty

\section{Introduction}

In patients with acute coronary syndromes, intracoronary thrombus is present in a high proportion and in associated with adverse outcomes ${ }^{1,2)}$. Although several anti-platelet agents, such as thienopyridine and glycoprotein II b-III a receptor antagonist, have been providing a better outcome of the treatment of this kind of lesion, it is still an important technical issue to elucidate how to effectively treat thrombus-containing lesions in coronary intervention ${ }^{3,4)}$. Intracoronary thrombolysis by selective administration of a fibrionlytic agent has been used with and without percutaneous coronary intervention (PCI) to treat patients with intracoronary thrombus. This case shows that intracoronary thrombolysis deserves reconsideration as an

Address for correspondence: June Hong Kim, Department of Internal Medicine, Pusan National University School of Medicine, Division of Cardiology, Cardiovascular Center, Pusan

National University Yangsan Hospital

E-mail: junehongk@gmail.com

Received: November 2, 2009

Accepted for publication: December 4, 2009 adjunct to PCI in selected cases, such as massive intracoronary thrombosis.

\section{Case Report}

A 67-year-old man presented at the emergency room with sudden and persistent chest pain (CCS III) and dyspnea (NYHA II) for 3 days. His cardiac risk factor was diabetes and he had a medical history of anterior myocardial infarction 3 years previously. On admission, his blood pressure was 100/60 $\mathrm{mmHg}$ and his heart rate was $66 \mathrm{bpm}$. The 12-lead ECG showed ST segment elevation in leads II, III, aVF and pathologic Q waves in leads III and aVF, as well as leads V14. The cardiac markers were elevated: troponin I was $73.12 \mathrm{ng} / \mathrm{mL}$ and CK-MB was $76.7 \mu / \mathrm{L}$. The patient received oral aspirin $300 \mathrm{mg}$ and clopidogrel $600 \mathrm{mg}$ as well as intravenous unfractionated heparin (bolus 4,000 IU, infusion $80 \mathrm{IU} /$ hour). Coronary angiography was performed immediately via the right femoral artery with $5 \mathrm{Fr}$ Judkins catheter (Cordis, USA). Left coronary angiography showed diffuse $90 \%$ stenosis at the proximal left anterior descending artery and tubu- 

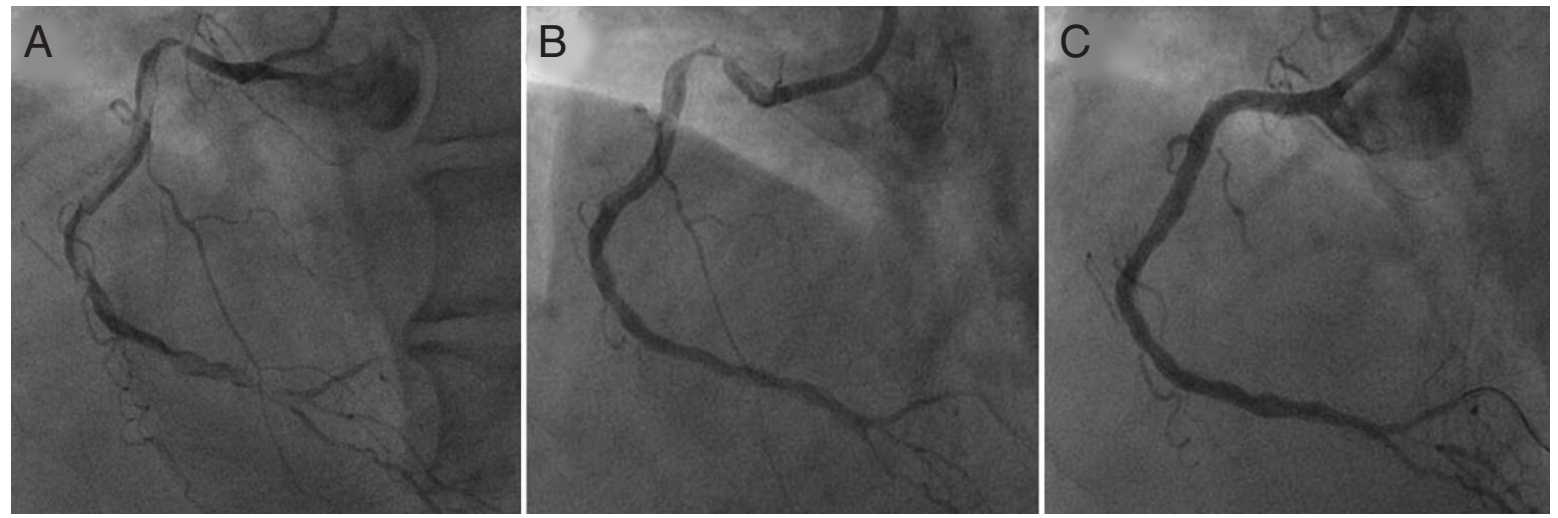

Fig. 1.

A. Baseline coronary angiography illustrating right coronary artery with massive intracoronary thrombosis with TIMI grade 2 distal flow.

B. Repeated angiography after intracoronary infusion of alteplase showing marked dissolution of thrombus with TIMI grade 3 distal flow.

C. Final coronary angiography showing successful revascularization of the right coronary artery.

lar 90\% stenosis at the left circumflex artery near the bifurcation of the first obtuse marginal branch, respectively. Right coronary angiography revealed massive intracoronary thrombosis occupying most of the lumen of the ight coronary artery with TIMI grade 2 distal flow (Fig. 1-A). Because the patient and his family were reluctant to consent to surgery, we planned PCI, but we were concened about massive intracoronary thrombosis and additionally, given the poor LV systolic function, no-reflow phenomenon or thrombus propagation to the distal coronary artery after revascularization could lead to fatal results. Thrombus aspiration did not seem to be effective because of the extremely heavy and large thrombus burden. Nonetheless, cardiac MRI showed a significant amount of viable myocardium in the RCA region (Fig. 2), so we decided to try intracoronary thrombolysis: alteplase 10 $\mathrm{mg}$ was injected as a bolus dose, and $90 \mathrm{mg}$ was infused via a 7Fr Amplatz's guiding catheter (AR1) for 90 minutes subsequently $(1 \mathrm{mg} / \mathrm{min})$. Repeated coronary angiography was performed soon after intracoronary thrombolysis. Surprisingly, the heavy thrombus almost completely dissolved and only a small amount remained in the mid-RCA with restoration of TIMI grade 3 distal flow (Fig. 1-B). A 0.014 inch guidewire (BMW universal ${ }^{\circledR}$; Guidant, USA) was introduced into the RCA lesion and predilatation was performed with a $3.0 \times 20 \mathrm{~mm}$ balloon (Ryujin ${ }^{\circledR}$; Terumo, Japan) at $16 \mathrm{~atm}$. Then, a $3.5 \times 24 \mathrm{~mm}$ bare metal stent (Driver ${ }^{\circledR}$; Medtronics, USA) was implanted at 18 atm into the proximal RCA lesion. Final angiography showed successful revascularization of the RCA (Fig. 1-C). The patient's clinical condition was stabilized after PCI without any bleeding complications

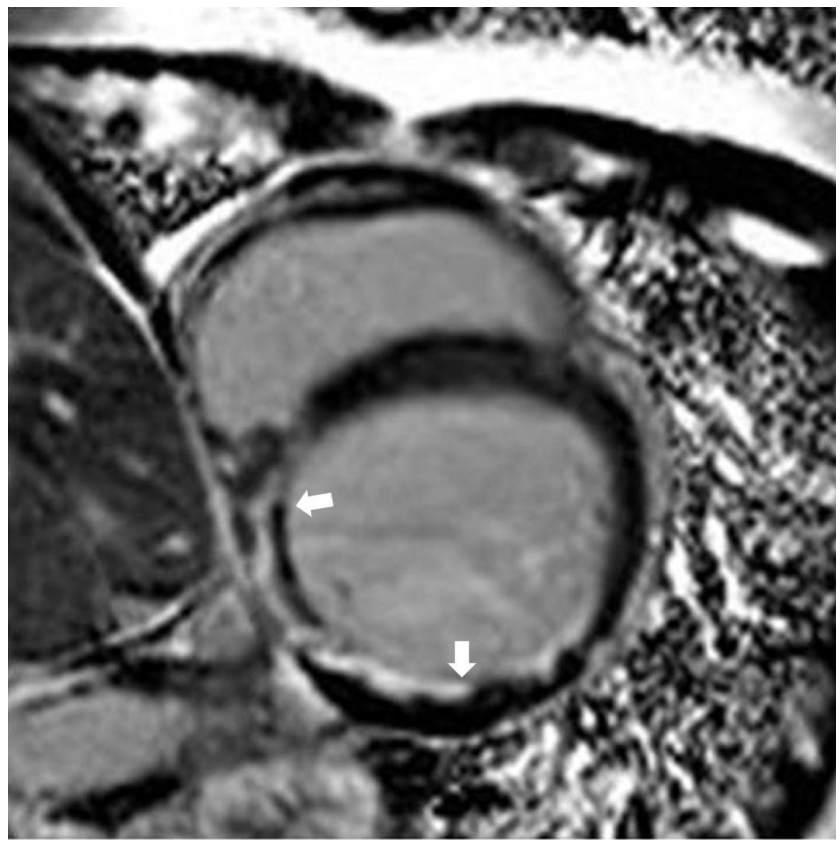

Fig. 2. Cardiac MRI shows an area of subendocardial enhancement, localized bright zone (white arrows), in the left ventricular inferior wall, which was corresponding to subendocardial infarction of RCA territory.

and he was discharged 10 days later.

\section{Discussion}

In the 1980s, before the era of coronary stents, when PTCA was introduced as a therapy for chronic coronary artery disease, there was considerable interest in the local delivery of thrombolytic agents for the 
treatment of complicated coronary artery diseases and acute myocardial infarction.

Angiographic resolution of intracoronary thrombus has been variable after intracoronary thrombolysis before angioplasty, but the results have largely been discouraging ${ }^{5-8)}$. As a result, intracoronary thrombolysis is rarely used in clinical practice; however, several studies still support the usefulness of intracoronary thrombolysis in selected cases. For instance, intracoronary t-PA registry investigators found significant improvements in the coronary TIMI flow grade and thrombus dissolution with intracoronary t-PA in 198 patients $(206 \text { cases })^{9)}$. Gurbel PA et al. found that lesion-directed delivery of alteplase resulted in more prolonged local thrombolysis and thrombus score reduction in 45 unstable angina patients with coronary thrombus ${ }^{10)}$. Recently, Kelly RV et al. reported that the administration of intracoronary thrombolytics (tenecteplase) in complex PCI after the onset of thrombotic complications is safe and may even improve the success rate in PCI complicated by thrombus in the study of 34 patients (22 with acute ST elevation MI, 4 with rescue PCI, 6 with non-ST elevation MI, and 2 during elective $\mathrm{PCI})^{11)}$. Additionally Hara et al. demonstrated in their report that the incidence of noreflow was lower and the angiographical success rate was higher for thrombolysis than angioplasty in acute myocardial infarction patients with thrombus-rich lesions ${ }^{12)}$.

We hope that our case will support the usefulness of intracoronary thrombolysis adjunct to PCI in specific situations and selected cases.

\section{References}

1) Mizuno K, Satomura K, Miyamoto A, Arakawa K, Shibuya T, Arai T, Kurita A, Nakamura H, Ambrose J: Angioscopic evaluation of coronary-artery thrombi in acute coronary syndromes. N Engl J Med, 1992; 326: 287-291

2) Falk E: Unstable angina with fatal outcome: dynamic coronary thrombosis leading to infarction and/or sudden death. Autopsy evidence of recurrent mural thrombosis with peripheral embolization culminating in total vascular occlusion. Circulation, 1985; 71: 699-708
3) Sugrue D, Holmes DJ, Smith H, Reeder G, Lane G, Vlietstra R, Bresnahan J, Hammes L, Piehler J: Coronary artery thrombus as a risk factor for acute vessel occlusion during percutaneous transluminal coronary angioplasty: improving results. Br Heart J, 1986; 56: 62-66

4) Arora R, Platko W, Bhadwar K, Simpfendorfer C: Role of intracoronary thrombus in acute complications during percutaneous transluminal coronary angioplasty. Cathet Cardiovasc Diagn, 1989; 16: 226-229

5) Ambrose J, Torre S, Sharma S, Israel D, Monsen C, Weiss M, Untereker W, Grunwald A, Moses J, Marshall J: Adjunctive thrombolytic therapy for angioplasty in ischemic rest angina: results of a double-blind randomized pilot study. J Am Coll Cardiol, 1992; 20: 1197-1204

6) Ambrose J, Hjemdahl-Monsen C, Borrico S, Sherman W, Cohen M, Gorlin R, Fuster V: Quantitative and qualitative effects of intracoronary streptokinase in unstable angina and non-Q wave infarction. J Am Coll Cardiol, 1987; 9: 1156-1165

7) Goudreau E, DiSciascio G, Vetrovec G, Chami Y, Kohli R, Warner M, Sabri N, Cowley M: Intracoronary urokinase as an adjunct to percutaneous transluminal coronary angioplasty in patients with complex coronary narrowings or angioplasty-induced complications. Am J Cardiol, 1992; 69: 57-62

8) DiSciascio G, Kohli R, Goudreau E, Sabri N, Vetrovec G: Intracoronary recombinant tissue-type plasminogen activator in unstable angina: a pilot angiographic study. Am Heart J, 1991; 122(1 Pt 1): 1-6

9) Intracoronary t-PA registry investigators. Clinical experience with intracoronary tissue plasminogen activator: results of a multicenter registry. Intracoronary t-PA Registry Investigators. Cathet Cardiovasc Diagn, 1995; 34: 196201

10) Gurbel P, Navetta F, Bates E, Muller D, Tenaglia A, Miller M, Muhlstein B, Hermiller J, Davidson C, Aguirre F, Beauman G, Berdan L, Leimberger J, Bovill E, Christenson R, Ohman E: Lesion-directed administration of alteplase with intracoronary heparin in patients with unstable angina and coronary thrombus undergoing angioplasty. Cathet Cardiovasc Diagn, 1996; 37: 382-391

11) Kelly R, Crouch E, Krumnacher H, Cohen M, Stouffer G: Safety of adjunctive intracoronary thrombolytic therapy during complex percutaneous coronary intervention: initial experience with intracoronary tenecteplase. Catheter Cardiovasc Interv, 2005; 66: 327-332

12) Hara M, Saikawa T, Tsunematsu Y, Sakata T, Yoshimatsu $\mathrm{H}$ : Predicting no-reflow based on angiographic features of lesions in patients with acute myocardial infarction. J Atheroscler Thromb, 2005; 12: 315-321 